\title{
Ancient Bruises: a Case of Skin Lesions Due to Vitamin C Deficiency
}

\author{
Dipti Rao, Roeland F. Stolk, Maaike H. de Blauw, Marcel M.C. Hovens, Robert-Jan Hassing \\ Department of Internal Medicine, Rijnstate Hospital, Arnhem, the Netherlands
}

Received: 19/09/2015

Accepted: 20/09/2015

Published: 19/10/2015

How to cite this article: Rao D, Roeland F. Stolk RF, de Blauw MH, Hovens MMC, Hassing RJ. Ancient bruises: a case of skin lesions due to vitamin C deficiency EJCRIM 2015;2:doi:10.12890/2015_000297.

Conflicts of Interests: The authors declare that there are no competing interests.

This article is licensed under a Commons Attribution Non-Commercial 4.0 License

\section{ABSTRACT}

Scurvy was a common 18th century disease caused by vitamin C deficiency. It presents with multiple non-specific symptoms and can lead to capillary fragility due to impaired collagen synthesis. We report the case of a 63-year-old woman who presented with fatigue, nausea and progressive skin lesions consisting of multiple ecchymoses on the legs as also described in the diary drawings of a navy doctor in the 19th century. The ascorbic acid level was undetectable low in the patient's serum. However, treatment with 500 mg ascorbic acid daily dramatically improved the skin lesions within 5 days.

\section{LEARNING POINTS}

- Scurvy is still prevalent in patients experiencing psychiatric disorders, social isolation and gastro-intestinal disorders.

- Scurvy can present with a wide range of symptoms and should be considered in the differential diagnosis of ecchymosis.

- Vitamin C deficiency can be treated with ascorbic acid 300-1000 mg daily for at least 1 month.

\section{KEYWORDS}

Scurvy; ascorbic acid; ecchymosis; psychiatric disease.

\section{INTRODUCTION}

Scurvy (Latin "scorbutus") was a common disease in the 18th century and caused by vitamin C (ascorbic acid) deficiency ${ }^{[1]}$. Although reports are rare, scurvy is still prevalent in certain risk groups, such as patients with gastro-intestinal disease, poor nutrition, psychiatric disorders, alcoholism or social isolation ${ }^{[2,3]}$. We report a case of scurvy in a patient with a psychiatric disorder with a presentation corresponding to the drawings of a 19th century navy doctor.

\section{CASE PRESENTATION}

A 63-year-old woman presented with fatigue, nausea and progressive skin lesions. The skin lesions had started 3 months previously as small spots (1-2 mm) on the lower legs and had spread up to the knee. She had no medical history. The year before, she had developed abdominal complaints for which she had adopted a diet consisting solely of crackers. She did not use any medication and did not smoke, drink alcohol or use drugs. She had not experienced any gingival bleeding. On physical examination she had a pale skin. There were multiple petechiae on both lower legs with ecchymoses on the dorsal side of the upper legs (Fig. 1). Further physical examination was unremarkable. Laboratory results showed a normocytic anaemia (haemoglobin of $4.7 \mathrm{mmol} / \mathrm{l}$ ), thrombocytes of $408 \times 10^{3} / \mu \mathrm{l}$ and C-reactive protein of $48 \mathrm{mg} / \mathrm{l}$. 
The particular clinical aspects and dietary history led to the clinical diagnosis of symptomatic scurvy caused by vitamin $\mathrm{C}$ deficiency. The patient's serum ascorbic acid level was undetectably low. She was treated with $500 \mathrm{mg}$ ascorbic acid daily, after which the ecchymoses improved dramatically within 5 days. Further analysis by a psychiatrist revealed delusional conceptions concerning food intolerance, possibly explained by a delusional disorder or schizophrenia.

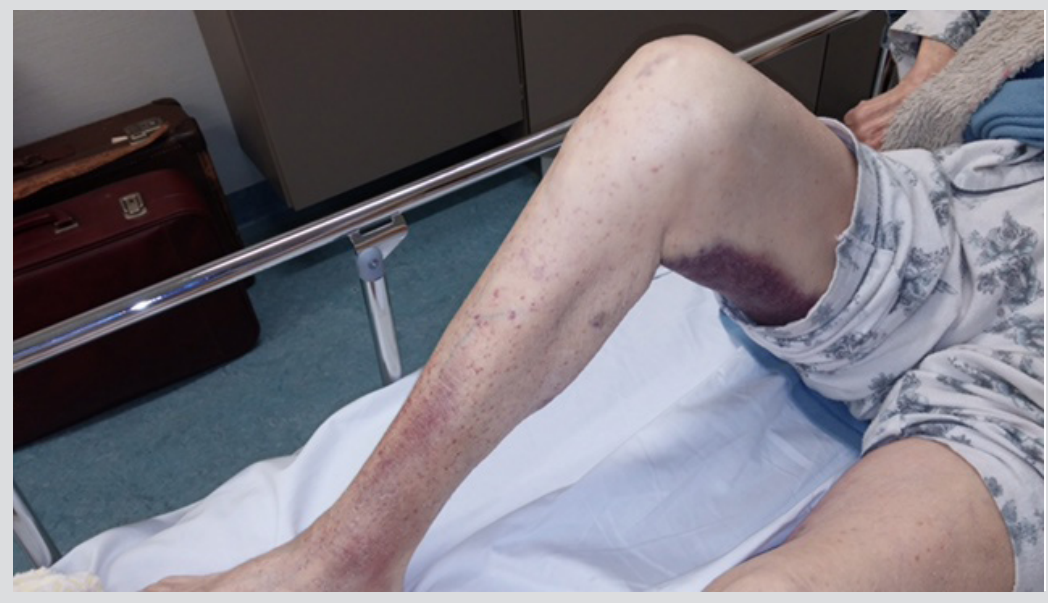

Figure 1. Clinical presentation: petechiae and ecchymoses on the dorsal side of the right leg

\section{DISCUSSION}

Scurvy was a common illness among seafarers and is estimated to have affected 2 million sailors between 1500 and $1800^{[1,4]}$. In 1747, James Lind conducted a trial of six different treatments (varying from sea water and herbs to vinegar) for 12 sailors with scurvy: only oranges and lemons were effective in treating the condition ${ }^{[1]}$. An illustration from the journal of Henry Walsh Mahon showing the effects of scurvy, from his time aboard HM Convict Ship Barrosa is shown in Fig. 2. The appearance of our patient shared many similarities with the third drawing in this figure.

Ascorbic acid is absorbed from the ileum and is a reversible biological reductant for reactions and metabolic processes. One of these processes is collagen synthesis for stabilization of the vascular wall, in which vitamin $\mathrm{C}$ functions as cofactor. Impaired collagen synthesis causes fragile capillaries, leading to erythrocyte extravasation and bleeding ${ }^{[5]}$.

The earliest symptom of scurvy is fatigue. Other symptoms include arthralgia, myalgia and depression. Cutaneous manifestations include follicular hyperkeratosis, perifollicular haemorrhages, ecchymoses, xerosis, leg oedema, poor wound healing and coiled body hairs. Gum abnormalities are frequently seen in patients with vitamin C deficiency. Anaemia, hypotension and shock are also possible ${ }^{[2,3]}$.

Diagnosis is based on measurement of serum ascorbic acid levels. Scurvy is treated with ascorbic acid supplementation with 300-1000 mg daily for at least 1 month, which results in rapid improvement with the cutaneous manifestations resolving in a few weeks ${ }^{[2,5]}$.

In conclusion, scurvy is a known historical disease but it is still found in some patients, such as those with psychiatric disorders. Scurvy can present with a wide range of symptoms, and should be considered in the differential diagnosis of ecchymosis.

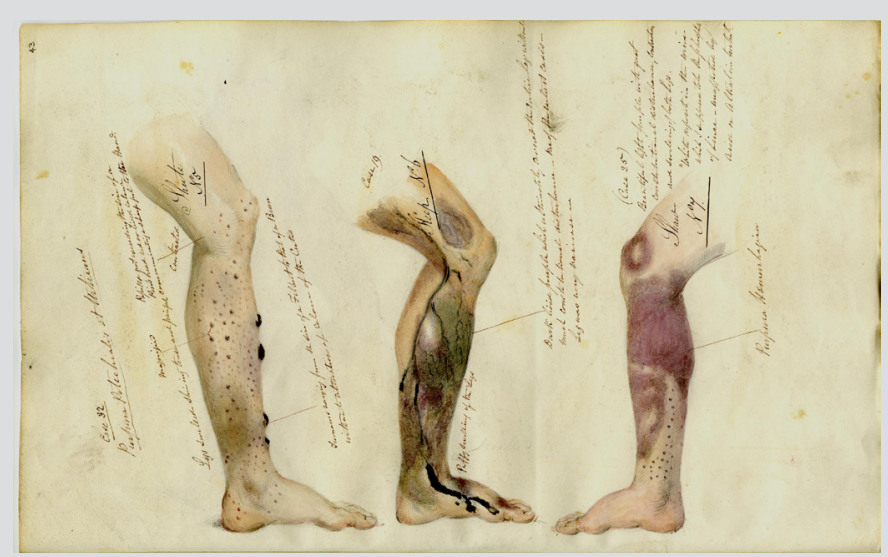

Figure 2: Barrosa convict ship, illustrations of the effects of scurvy by Dr Mahon, 1841-1842.

Copyright: The National Archives (United Kingdom) 


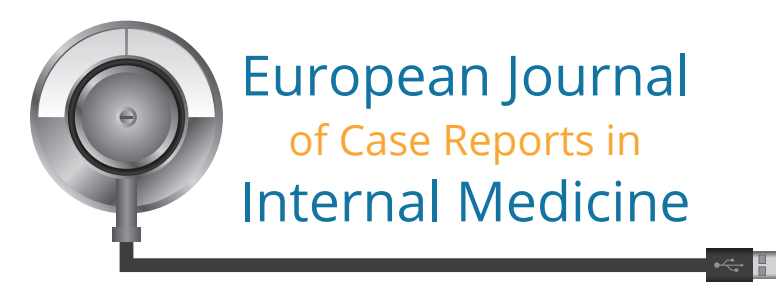

\section{REFERENCES}

1. Carpenter KJ. The discovery of vitamin C. Ann Nutr Metab 2012;61:259-264.

2. Hirschmann JV, Raugi GJ. Adult scurvy. J Am Acad Dermatol 1999;41:895-906.

3. Olmedo JM, Yiannias JA, Windgassen EB, Gornet MK. Scurvy: a disease almost forgotten. Int J Dermatol 2006;45:909-913.

4. McCord CP: Scurvy as an occupational disease. J Occup Med 1971;13:306-307,348-351,393-395,441-447,484-491,586-592

5. Michiels M, Mellema M, Peters FP. Haemorrhages due to vitamin C deficiency. Scurvy in the 21st century. Ned Tijdschr Geneeskd 2010;154:A1638. 